\title{
College Algebra in Context: A Project Incorporating Social Issues
}

\section{Michael T. Catalano}

Mathematics Department, Dakota Wesleyan University, Mitchell, SD, micatala@dwu.edu

Follow this and additional works at: https://digitalcommons.usf.edu/numeracy

Part of the Mathematics Commons, and the Science and Mathematics Education Commons

\section{Recommended Citation}

Catalano, Michael T.. "College Algebra in Context: A Project Incorporating Social Issues." Numeracy 3, Iss. 1 (2010): Article 7. DOI: http://dx.doi.org/10.5038/1936-4660.3.1.7 


\title{
College Algebra in Context: A Project Incorporating Social Issues
}

\begin{abstract}
This paper discusses the development of an innovative college algebra text designed for use in a datadriven, activity-oriented college algebra course, incorporating realistic problem situations emphasizing social and economic issues, including hunger and poverty, energy, and the environment. The course incorporates quantitative literacy themes, is informed by existing college algebra texts within the college algebra reform movement, and implements a collaborative pedagogical approach intended to provide future $\mathrm{K}-12$ teachers an alternative model for the teaching of mathematics. The paper contains a short history of the project development phase, supported by an NSF grant (DUE \#0442979), as well as the perceived role of the project in the college algebra reform and quantitative literacy movements. We make a short case for redefining the content of a college algebra course and acknowledging that for many students, it has become a terminal mathematics course. A description of the contents of the text, its relation to more traditional college algebra content, and four example student activities are included (on the topics of homelessness, the effects of airline deregulation, real estate versus savings as investment instruments, and the 2008 election). A summary of evaluation and assessment data from five years of pilot-testing, done primarily in conjuction with our NSF grant evaluation plan, is provided.
\end{abstract}

\section{Keywords}

College Algebra, Quantitative Literacy, Social Issues

Creative Commons License

(c) (1) (9)

This work is licensed under a Creative Commons Attribution-Noncommercial 4.0 License 


\section{Introduction}

The college algebra reform movement and the quantitative literacy (QL) movement have both been with us for roughly two decades. Madison and Steen (2008) provide a brief history of the latter along with a discussion of the ambiguity and multiple usages of the terms QL, quantitative reasoning, and numeracy. Two milestones in the QL movement were the American Statistical Association's Quantitative Literacy project in the mid-1980's and the establishment of the Subcommittee on Quantitative Literacy Requirements of the Committee on the Undergraduate Program in Mathematics (CUPM) in 1989. QL has gained added prominence within the mathematics community in the present decade, as indicated by the establishment of the MAA's special interest group on quantitative literacy (SIGMAA QL) and the National Numeracy Network.

Concerning the college algebra reform movement, the MAA publication, $A$ Fresh Start for Collegiate Mathematics (Baxter Hastings et al. 2006), while not focusing solely on college algebra, includes several articles on the role of this course in the curriculum. Many of the well-known college algebra reform projects are represented that book.

This article describes a college algebra course and text that is intended to fit into both movements, the history and current status of the project, a summary of assessment information, and how the project differs from some of the existing college algebra reform projects. Work on this project was supported by an NSF CCLI-EMD grant, DUE \#0442979, College algebra in Context: A Learnercentered Approach Incorporating Data-Driven Activities Related to Social Issues. ${ }^{1}$ Preliminary versions of our text have been titled Algebra: Modeling Our World $(A M W)$.

$A M W$ is designed for use in a learner-centered, inquiry-intensive, data-driven, activity-oriented college algebra course, incorporating realistic problem situations emphasizing social and economic issues, including hunger and poverty, energy, and the environment. The initial goals included a desire to address a need for citizens with a greater level of QL and a need for improved mathematics education for $\mathrm{K}-12$ teachers.

$A M W$ in its various developmental stages has been used in all sections of college algebra at Dakota Wesleyan University (DWU), an institution of approximately 700 students, since the fall of 2004. We should say up front that the small size of DWU and its mathematics department has led to some idiosyncratic features of the text and the project. In particular, starting in the fall of 2004 through the spring of 2009, I have taught all the college algebra at DWU,

\footnotetext{
${ }^{1}$ So named to avoid confusion with Harshbarger and Yocco (2004), College algebra in Context with Applications for the Managerial, Life, and Social Sciences.
} 
save for summer school. Finally, both my colleagues in the mathematics department and the administration at DWU have been supportive of my work on $A M W$, so I have not experienced the political barriers that many reform projects are presented with.

\section{Project History}

Initial work on $A M W$ began in the fall of 2003. The motivation for commencing this project included several factors which those familiar with college algebra reform will recognize. Our existing traditionally oriented college algebra course suffered from less-than-satisfactory success rates, defined principally in terms of the percentage of students completing the course with a passing grade. Many students did not see the relevance of the material for their academic and career plans. Also, an increasing number of our college algebra students were elementary education majors, and there was concern that negative attitudes towards mathematics that some of these students brought into the course were only being reinforced and would ultimately be passed on to their future students. The increase in students was a result of a decision by the college's Education Department to require college algebra in order to comply with new requirements enacted by the state of South Dakota. From the fall of 2005 through the fall of 2008, 24\% of college algebra students at DWU were elementary education majors, and this was down from over $40 \%$ in some years during the early part of the decade. No other major requires college algebra, and the majors represented have tended to reflect the overall distribution of majors at DWU, with criminal justice, business, psychology, athletic training, nursing, and undecided students predominating. Roughly one-third of enrollments in 100- and 200-level classes at DWU are in college algebra.

Finally, as at many institutions around the country (see Baxter Hastings et al. 2006), college algebra was not serving as a gateway to other courses, especially calculus, but was rather a terminal mathematics course for most students, except for elementary education majors who subsequently took Mathematics for Elementary Education and students of various majors who took an introductory statistics course. In fact, from the fall of 2005 through the fall of 2008, not a single student who took college algebra subsequently enrolled in calculus within this period. Our anecdotal evidence indicates that since 2000 perhaps a halfdozen college algebra students eventually took calculus. Over two-thirds of our calculus enrollments are freshman, and those taking a college mathematics course prior to calculus typically take a College Algebra and Trigonometry course which is still offered in a traditional mode.

Given the perceived problems with the course and its terminal nature for most students, I decided as department chair and the person teaching all of our 
college algebra at the time that we needed to improve the situation. A number of the reform texts in existence at that time were considered, including Schaufele, Zumoff (1999), Barrett and The North Carolina School of Science and Mathematics (2000), Kime, Clark et al. (2001), Kenschaft (2002), Crauder, Evans, and Noell (2003), Small (2004), and Gordon et al. (2004).

However, several considerations led me to embark on the "do it yourself" project from which $A M W$ developed. The first was a desire to take an even more radical approach to incorporating data and real-world situations into the course than most of the existing reform models. The second was a desire for a text that was shorter, more succinct, and more conversational or narrative in style. Thirdly, Dakota Wesleyan was in the process of developing the McGovern Center for Leadership and Public Service. Senator McGovern is DWU's most noted alumnus and his later career has been devoted to developing solutions to world hunger and poverty. Given my own interest in social issues, I felt a text which incorporated data and problem situations related to hunger, poverty, and other social issues would both be of interest to me (and hopefully my students) and support the mission of the McGovern Center.

Finally, I had been familiar with the development of the General Education in Mathematics and Science (GEMS) program at Hope College. In the early 2000's, this program included a two-credit mathematics general education course entitled Mathematics for Public Discourse using a home-grown text by the same name. This text has now been published by the MAA under the title Understanding Our Quantitative World (Andersen and Swanson 2005), referred to as $U Q W$ below. The course (GEMS 100) was meant to articulate with the other science general education courses at Hope, leading to a rather unique and idiosyncratic selection of course content. $U Q W$ includes chapters on periodic functions, multivariable graphs and functions, and random sampling, topics not typically included in a college algebra course. It also includes several chapters covering basic descriptive statistics, regression, and correlation. It does not include discussion of sequences and series, logistic functions, permutations and combinations, and has only a few exercises related to solving equations. Thus, while there is considerable overlap in content between $U Q W$ and $A M W$, there are also significant differences and the former probably would not be considered appropriate for a college algebra course by many mathematics faculty members.

I think it is likely that some may feel $A M W$ is also too far from the traditional college algebra content and emphasis on skills to bear that name, and the reader can make his or her own judgment on this after perusing the details of $A M W$ outlined below. However, in my view, one of the issues raised by the college algebra reform movement is the very definition of "college algebra." To the extent that college algebra's de facto role in the mathematics curriculum has already changed in many contexts from one of preparation for calculus to that of a 
terminal general education course, the definition has already changed. I would allow using "college algebra" to describe our course using $A M W$ is stretching the definition at least a bit, but I also believe the content is close enough to traditional college algebra to legitimate the use of the term.

In addition to its somewhat idiosyncratic content, $U Q W$ incorporates a collaborative pedagogical approach which I felt would provide a number of advantages in our college algebra setting, in particular providing future elementary teachers with a different model for the teaching of mathematics. In both GEMS 100 using $U Q W$ and college algebra using $A M W$, students typically spend roughly half of the class time in a typical week working together in groups of two or three.

I decided to use $U Q W$ as a principal model for my own text and was fortunate to be able to spend the 2003-2004 school year on sabbatical at Hope, teaching GEMS 100 and beginning work on my own project. NSF funding for $A M W$ began in May of 2005 and expired in April of 2009, and I hope to investigate publication of the text in the near future. The NSF funding supported my work in developing the text, evaluation activities, travel and dissemination activities, and provided a mobile laptop computer lab for use in pilot sections.

\section{Course Content and Characteristics}

The content of a typical traditional college algebra course includes a review of operations on algebraic expressions and solving equations, and then it moves on to the study of the general concept of a function and the specific families of linear, polynomial, rational, radical, exponential, and logarithmic functions. Function inverses and compositions, sequences and series, systems of linear equations (often via matrix methods), basic counting techniques and probability also typically make an appearance. Sometimes mathematical induction, logistic and other more exotic functions, transformations of functions, complex numbers and DeMoivre's theorem, systems of inequalities and linear programming are also included. As noted by Small (2006), this choice of topics dates to the 1950's where college algebra was seen as preparation for calculus. Prior to implementation of $A M W$, college algebra included all of these except induction, complex numbers, systems of inequalities and linear programming, and matrices.

Taking into account the reality that college algebra is now a terminal course for most students who take it, $A M W$ omits some of the traditional topics while adding others as reflected by the following brief table of contents.

1. Introduction

2. Representing Quantitative Information

3. Collecting and Analyzing Data

4. Functions 
5. Linear Functions

6. Exponential and Logarithmic Functions

7. Power and Quadratic Functions

8. Transformations of Functions

9. Other Families of Functions

10. Adding Things Up

11. Probability

The most conspicuous omissions from the traditional list are polynomial, rational, and radical functions, and systems of equations. Composition of functions is included, but not much on inverse functions. Rational and radical functions do make an appearance in the guise of power functions, but long division, the factor and remainder theorems, and operations on radical or rational expressions are not included. Counting techniques, permutations, combinations, and conditional probability are included in the last chapter.

In addition, the focus is on the use of algebraic techniques and functions to model real-world data. When equations are solved, the variable being solved for is either the output or more frequently the input of a modeling function. Each family of functions is introduced in the context of a real-world example. While traditional methods of fitting lines or exponential functions to two given points are covered, function models are more often developed using regression. We included linear and exponential regression in our traditional college algebra course, but $A M W$ makes much greater use of these as well as power and logarithmic regression.

Because so much of the course is based on real-world data, we include two chapters on elementary descriptive statistics. These chapters include discussion of sampling, bias and variability, measures of central tendency including weighted averages, standard deviation and confidence intervals, and correlation. Certainly these chapters address common QL goals like understanding quantitative information within real-world contexts, using this understanding along with appropriate mathematical and statistical techniques to solve problems, reaching conclusions and critiquing statements based on a given set of information, and realizing that many statements come with an associated probability of certainty and how to estimate that probability. The inclusion of basic statistics as well as the emphasis on and treatment of probability is in part intended to address the increasing importance of these topics in the K-12 curriculum. As noted below, roughly 1 in 4 of our students are Elementary Education majors.

I would say that this course content represents a significant shift in priorities and certainly leaves out a lot of the traditional material. In an era where many institutions are still teaching college algebra in the traditional mode, this does present potential problems for students who transfer, and potentially for those few 
of our own students who do go on to calculus. As noted above, the latter is a rare occurrence at DWU.

\section{Characteristics of the Text}

The format of $A M W$ is largely modeled after $U Q W$. In particular, student exercises are grouped into two types. The first are referred to as "Reading Questions" and are designed to be straightforward and simple enough that most students can complete them based on the reading without necessarily having examples done in class beforehand. The second are referred to as "Activities and Class Exercises." These are more involved and sometimes less well-defined exercises, usually involving real-world data, and intended for use by students in groups, although they could be done individually as well. We provide some examples in the next section of this paper.

The text requires the use of technology, most importantly the ability to produce graphs, including scatter plots, and linear and non-linear regressions. We have been predominantly using Fathom Dynamic Data software. Microsoft Excel or even a standard graphing calculator would suffice for the vast majority of exercises, and this fall we have one section using Excel rather than Fathom. Activities requiring Fathom can certainly be omitted without any harm. Fathom presents several advantages over Excel, including a more intuitive user interface; a much shorter learning curve for students; ease in incorporating text, graphs, tables and calculations in one document; and several unique dynamic features specifically designed to help students learn mathematics and statistics. Two disadvantages of Fathom relative to Excel are that Fathom has no built-in nonlinear regression features, and students are not likely to use Fathom outside of a mathematics classroom or after college.

\section{Example Activities}

When we say AMW incorporates real-world data, this includes not only examples in the text, but even more importantly the activities which students work on in groups. Students used tablet computers and graphing calculators for these, and completed activities were submitted and graded electronically. The tablet computers allow students to include hand-drawn graphs and the instructor to include written comments in grading student work. Here are a few example topics included in AMW:

- Quantification of hunger and poverty, and investigation of variables associated with hunger and poverty. Data used includes, for example, national poverty rates, child mortality rates, and malnutrition rates. 
- Income inequality in general, and as measured by the so-called Gini Coefficient in particular (see also Catalano, Leise, and Pfaff 2009).

- Weighted averages and indices, including stock indices, the NFL quarterback rating system, and the Social Capital Index, the latter introduced by Putnam (2001).

- Energy consumption and production models, including so-called Hubbert curves (e.g., Deffeyes 2001). Energy production and consumption data from the U.S. and other countries are available from the U.S. Department of Energy Web site.

- Inflation, real and constant dollars, and adjusting monetary quantities for inflation. Data used include Consumer Price Index data from the Bureau of Labor Statistics and time series for gasoline prices, cost of computer storage, and other data on nominal prices.

- Life expectancy versus other variables, such as literacy rates.

- Use of geometric series to model savings plans.

- Models for child mortality.

- Interpretation of medical test results.

- Use of probability to measure and compare risks (e.g., risk of being killed by terrorists versus being struck by lightning).

- Investigation of relationships between vehicular greenhouse gas emissions and engine size, vehicle price, gas mileage, etc. using data from a variety of car models.

To give a better flavor of the types of group activities that students are engaged with, here are four examples from the text. ${ }^{2}$

Example 1 is from Chapter Three, "Collecting and Analyzing Data." The goal is for students to evaluate a claim that includes a statement about averages, and to investigate how a histogram for data consistent with this claim would look.

\section{Homelessness}

We noted in the text that there have been widespread reports that the average age of a homeless person is nine. Adam Molnar, a mathematics professor at Bellarmine University, found that this claim originated with ads created by the Coalition for the Homeless, which bills itself as the oldest homeless advocacy and direct service organization in the U.S.

\footnotetext{
${ }^{2}$ There is some slight rewording for the presentation in this paper.
} 
a. Create a set of five ages where the average age is nine, and then discuss how likely you think it would be to find a group of five homeless people with these ages.

b. Create a set of five ages where the average age of the five people is nine, and one of the people is 40 years old. Would you be likely to find a group of five homeless people with these ages?

c. Create a data set of 25 ages and an associated histogram so that the average of the 25 ages is nine. Use at least ten different ages, and include at least five adults in your histogram.

d. Describe the skew and other characteristics of your histogram.

e. How likely do you think it is that this claim is true? Describe how you might go about determining whether or not it is true.

Example 2 is from Chapter Six, "Exponential and Logarithmic Functions." The goals for this activity are for students to be able to wade through a fairly verbose problem description, understand the information and what is relevant, and to create some exponential models that fit two given data points. They then are asked to compare these models to critique a claim being made based on the given data and graph. Students are also asked to identify problems in the analysis in the report.

Airline Deregulation

The graph at the bottom of this box is from a report by the Heritage Foundation on airline deregulation. The foundation supported deregulation of the airline industry, and the report tries to make the case that based on 20 years of experience, deregulation has been good both for the industry as a whole and for consumers. The foundation cited this chart to support the claim that, after deregulation, the rate of increase in miles flown has been greater than the rate of increase prior to deregulation. This claim was meant to respond to critics of deregulation who have claimed that deregulation led to fewer options and a lower rate of service for consumers in many areas of the country. Here is a short excerpt from the report (Thierer 1998):

Airlines also are logging more miles than before deregulation. Whereas carriers flew roughly 2.5 billion miles in 1978, they logged more than double that number last year alone, flying approximately 5.7 billion miles in 1997. Furthermore, as Chart 5 illustrates, this trend increased much more rapidly after deregulation than it did before market liberalization.

a) The bars on the graph represent the actual number of miles flown by U.S. domestic carriers. What function family do you think 
would be most appropriate to model these data?

b) The black line, up to the year 1978, is meant to represent what is called the three-year moving average. This is typically done by taking the values of three consecutive years, including the year in question, and averaging them. What seems to be wrong with the three-year averages as plotted here?

c) In the excerpt from the report given above, it was noted that the trend of miles flown increased much more rapidly after deregulation than before. The implication is that more miles were flown after deregulation than would have been flown if deregulation had not occurred.

i. What function family is being used in creating the extrapolated trend line?

ii. In order to create the extrapolated line, the author probably calculated the linear trend line for years up to 1978. Why do you think the author would do this? What is wrong with using a linear model in this situation?

iii. The actual data on which the graph is based were given later in the report. The number of miles flown in 1950 was about 0.48 billion, and the number flown in 1970 was about 2.39 billion. Letting $t=0$ represent 1950 , use these two points to create an exponential model $M=a\left(b^{t}\right)$ where $M$ represents estimated number of miles flown and $t$ represents time in years from 1950.

iv. Use your exponential model to estimate the number of miles flown in 1980, 1990, and 1996. How do these values compare with those indicated by the graph?

v. One might argue that the years 1950 and 1970 used to create the previous model would lead to an overestimate, since the graph has a relative peak near 1970. Picking a lower point from a later year would give a different model with lower predictions for future years. In the year 1974, only 2.18 billion miles were flown. Use this point together with 1950 to create an exponential model, and then use this model to predict the number of miles flown in 1980, 1990, and 1996.

vi. What are the percentage increases in number of miles flown represented by your two exponential models?

d) Comparing your two exponential models to the actual data, and 


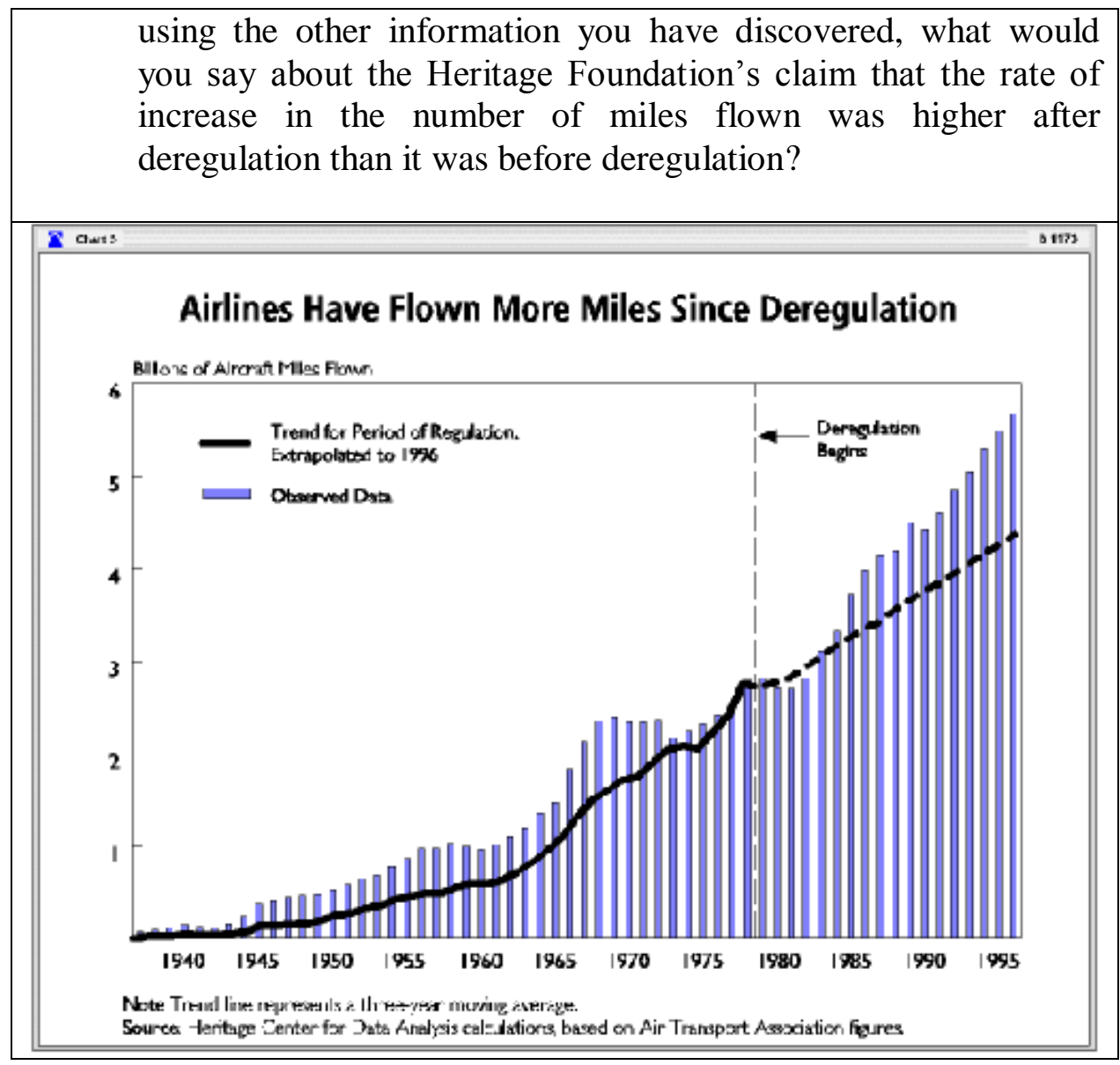

Example 3 is from Chapter 10, "Adding Things Up," where the main topic is sequences and series, particularly arithmetic and geometric sequences and series, which are introduced as linear and exponential functions restricted to the domain of natural numbers or a similar subset of integers. Geometric series are motivated through the example of savings plans where the interest rate is assumed to be constant. This brings in exponential functions in the form of the compound interest formula. The main goals are for students to gain some familiarity with the financial context, gain experience in calculating geometric series, learn to select the appropriate equation depending on the verbal context, and gain experience in determining the reasonableness of their calculations.

\section{Housing versus Saving as an Investment}

In the text, we calculated that at a $9 \%$ annual rate of interest, we could buy a house worth about $\$ 125,000$ with a monthly payment (not including taxes and insurance) of $\$ 1000$. We also estimated that this 
house, located in South Dakota, would be worth about $\$ 440,000$ in 30 years. In this activity, you will investigate what will happen if you decide to spend less on the house and invest the difference. Let's suppose you decide to buy housing at $\$ 800$ per month and invest $\$ 200$ per month in a savings plan.

a) What 30-year loan amount can you afford at a monthly payment of $\$ 800$ assuming a $6 \%$ annual interest rate?

b) Assuming you buy a house for the loan amount you found in (a), and assuming the same $4.287 \%$ percent growth rate in the value of your house as in the text, how much will your house be worth in 30 years?

c) Now, if you invest $\$ 200$ per month at $9 \%$ compounded monthly for 30 years, how much will the total balance be at the end of the 30 years?

d) Combining parts (b) and (c), what are your total assets between the house and the savings plan after the 30 years?

e) Now suppose you had spent the entire $\$ 1000$ per month on housing. Calculate the value of the house you could buy at $6 \%$ interest and how much this house would be worth after 30 years at the same $4.287 \%$ growth rate. How does this compare with your total in part $(\mathrm{d})$ ?

f) Can you think of any other information or assumptions that we haven't included here that might be included to make our comparison more realistic?

Example 4 is from Chapter Twelve, "Probability." Although the data are really just exit poll results, we couch the questions in terms of conditional probabilities. The goals of the activity include helping students gain understanding of conditional probabilities, and how to use quantitative information in answering "what if" questions.

\section{The 2008 election}

In any election, politicians are most concerned with the most basic question: Who wins? However, exit polls that indicate how different demographic groups voted are also of great interest. In this activity, we consider exit polling data from this past fall, accessed from http://www.cnn.com/ELECTION/2008/results/polls.main/ on December 30th of 2008. 


\section{Evaluation and Assessment}

As part of the evaluation process for our NSF grant we administered the Student Assessment of Learning Gains (SALG) survey, ${ }^{3}$ conducted a small number of interviews with students in focus groups after the first year, tracked student persistence and success rates, and analyzed of a few final exam items common to pilot sections and previous sections not using $A M W$. Although participation in particularly the SALG and the focus groups was limited, the results indicated that the project seemed to be meeting its goals, and the focus groups provided some more in-depth student feedback early in the development period that resulted in changes to both the text and some classroom practices. In particular, we now use both groups of two and three based on the recommendation of students.

SALG is a Web-based, free assessment instrument that can be modified by the individual instructor. Data from the SALG and focus groups indicated that students felt this course was more effective in helping them to learn mathematics than previous mathematics courses that they had taken in high school or college, and that the course structure assisted in this. Several students did suggest increasing the pace of the course early in the semester to save more time for the more difficult chapters later. Table 1 is a sampling of SALG results from three different semesters. As we did not make use of SALG prior to the initial use of $A M W$, we do not have any baseline data to use for comparative purposes.

Table 1.

Sample Results of the Student Assessment of Learning Gains

\begin{tabular}{llll}
\hline & $\begin{array}{l}\text { Fall 2006 } \\
(N=19)\end{array}$ & $\begin{array}{l}\text { Spring 2007 } \\
\text { avg (stdev) }\end{array}$ & $\begin{array}{l}\text { Fall 2007 } \\
(N=37)\end{array}$ \\
\cline { 2 - 4 } & & \\
How much did each of the following aspects of the class help your learning? (1, No help; 2, \\
A little help; 3, Moderate help; 4, Much help; 5, Very much help)
\end{tabular}

${ }^{3}$ http://www.salgsite.org (accessed Dec. 10, 2009). 


\begin{tabular}{|c|c|c|c|}
\hline \multicolumn{4}{|c|}{$\begin{array}{l}\text { As a result of your work in this class, how well do you think that you now understand each } \\
\text { of the following? (1, Not at all; } 2, \text { A little; } 3 \text {, Somewhat; } 4 \text {, A lot, } 5, \text { A great deal) }\end{array}$} \\
\hline $\begin{array}{l}\text { How algebra can be used to } \\
\text { understand real-world situations }\end{array}$ & $3.42(0.99)$ & $3.36(0.64)$ & $3.78(0.9)$ \\
\hline $\begin{array}{l}\text { How to interpret, analyze, and create } \\
\text { quantitative and graphical of } \\
\text { information }\end{array}$ & $3.53(1.14)$ & $3.36(0.77)$ & $3.76(0.85)$ \\
\hline Solving Problems & $3.37(1.04)$ & $3.27(0.62)$ & $3.7(1.06)$ \\
\hline $\begin{array}{l}\text { Understanding relevance of field to } \\
\text { real world }\end{array}$ & $3.47(1.04)$ & $3.36(0.64)$ & $3.76(0.85)$ \\
\hline Appreciating this field & $3.16(1.23)$ & $3.36(0.98)$ & $3.41(0.97)$ \\
\hline $\begin{array}{l}\text { Ability to think through a problem or } \\
\text { argument }\end{array}$ & $3.21(1)$ & $3.36(0.77)$ & $3.59(0.88)$ \\
\hline $\begin{array}{l}\text { Confidence in working with } \\
\text { quantitative information }\end{array}$ & $3(1.3)$ & $3.18(0.72)$ & $3.65(0.99)$ \\
\hline $\begin{array}{l}\text { Feeling comfortable with complex } \\
\text { ideas }\end{array}$ & $3.11(1.37)$ & $3.09(0.51)$ & $3.38(1)$ \\
\hline Enthusiasm for subject & $2.95(1.39)$ & $3(0.74)$ & $3.19(1.17)$ \\
\hline
\end{tabular}

How much of the following do you think you will remember and carry with you into other classes or aspects of your life? (1, Not at all; 2, A little; 3, Somewhat; 4, A lot, 5, A great deal)

$\begin{aligned} & \text { Ability to use mathematics in real- } \\ & \text { world situations. }\end{aligned}$
$\begin{aligned} & \text { Appreciation for the usefulness of } \\ & \text { math in understanding real-world } \\ & \text { situations. }\end{aligned}$

As a final comment on the SALG, I should point out that the survey was administered at the end of the semester. Early in the semester in many sections there was a fair amount of negative reaction to the activities and the real-world aspect to the course, partly because these aspects presented a new experience for students, and partly because students found the ambiguity inherent in some of the activities unsettling. Most students seemed to get past this within a few weeks.

In order to compare how student performance might be affected by the migration from a traditional approach to the reform approach represented by $A M W$, we examined performance on three common final exam items. The questions which were common to all reform and non-reform sections, except for minor alterations, were:

1. Find the equation of the line through the points $(6,7)$ and $(11,5)$.

2. Find the indicated sums. The sequence of terms may be arithmetic, or geometric, or neither.

a. $\quad \sum_{k=0}^{35} 100\left(1.08^{k}\right)$ 
b. $\quad \sum_{k=1}^{50}(8 k+3)$

3. Find the probability of rolling a sum of 6 when rolling two die.

On 1, a sample non-reform section from 2003 averaged $74 \%$ of the possible points for the question. The average for four reform sections from 2005 to 2008 was $70 \%$. On the series question, the non-reform average was $59 \%$, and the reform average was $48 \%$. On the probability question, the non-reform average was $44 \%$ and the reform average was $61 \%$ with all reform sections higher than the non-reform section. We expected there would be some degradation in skills, as these received less emphasis in the reform course, but the expected degradation did not seem to happen to any great extent. It should be noted that a higher percentage of students in non-reform sections withdrew from the course prior to the final (Table 2), which may mean averages for non-reform sections are slightly inflated compared to reform sections. Note also that average section sizes increased over time, and we increased from two sections to three sections per year between 2003 and 2004.

Student success rates, as measured by the percentage of students completing the course with a passing grade, and average grades in $A M W$ sections were significantly better than in previous sections (Table 2). Data were collected on five non- $A M W$ sections from 2000 through 2003 and 15 sections using $A M W$ from 2004-2009. The twelve 2005-2009AMW sections were taught in a mobile computer lab setting, and the three 2004-2005 AMW sections were taught using handheld graphing technology only. D grades over the last three semesters were $10.7 \%$ of enrollment, versus $7.6 \%$ the three semesters before that.

Table 2.

Comparisons Between Reform and Non-Reform Sections at DWU

\begin{tabular}{llllllll}
\hline & $\begin{array}{l}\text { Non- } \\
\text { reform } \\
(N=119)\end{array}$ & $\begin{array}{l}\text { Total } \\
(N=382)\end{array}$ & $\begin{array}{l}2004-05 \\
(N=72)\end{array}$ & $\begin{array}{l}2005-06 \\
(N=64)\end{array}$ & $\begin{array}{l}2006-07 \\
(N=78)\end{array}$ & $\begin{array}{l}2007-08 \\
(N=79)\end{array}$ & $\begin{array}{l}2008-09 \\
(N=89)\end{array}$ \\
\cline { 2 - 7 } $\begin{array}{l}\text { Avg. Section } \\
\text { Size }\end{array}$ & 23.8 & 24.3 & 24 & 21.3 & 26 & 26.3 & 29.7 \\
$\%$ completion & 76 & 90.8 & 87.5 & 84.4 & 91.0 & 95.0 & 93.3 \\
$\%$ A or B grades & 46 & 57.6 & 64 & 57 & 51.3 & 59.5 & 48.3 \\
$\%$ Attendance & & & & & $87^{*}$ & 91 & 89 \\
\hline
\end{tabular}

Notes: * Spring 2007

Percent completion rates (Table 2) were calculated by considering all students who completed the first week of class, and taking the percentage of these that completed the course with a passing grade. We have also calculated the percent of students who completed the course with A's or B's. It should be noted 
that the grading scheme for $A M W$ sections allowed students some amount of flexibility and, as a result, probably contributed to higher overall grades. We also began to include attendance in the grading scheme. However, combined with feedback from the focus groups, the SALG survey, and other more informal assessment done during the AMW courses, it does appear from Table 2 that the course resulted in students feeling more confident of success and more willing to stick with the course, even when the course was perceived as difficult. Several students commented that the use of collaborative learning was a great help to them.

Attendance rates for $A M W$ sections from the spring of 2007 through the spring of 2009 are also included in Table 2. Attendance for individual semesters ranged from $84 \%$ to $92 \%$, and was calculated by taking the total numbers of days attended by students and dividing by the total number of student days from a 45day semester. Attendance was taken every day and students could earn points towards their final grade from attendance - a practice that surely motivated students to attend. For example, in the spring of 2009, nine out of 33 students who began the course completed it with two or fewer absences for the whole semester (45 days). Another motivating factor was that students who missed a day typically did not receive full credit for any work their group did on that day. It certainly seems reasonable to believe that high attendance rates were one of the factors contributing both to reasonably good average grades and high completion rates in the course.

\section{Conclusion}

There are already a number of quality college algebra reform projects in existence, and in undertaking this project, I am certainly aware of the danger of reinventing already well-oiled wheels. On the other hand, $A M W$ does provide a model for college algebra reform that is significantly different from the more well-known existing reform texts in several ways. $A M W$ is designed to be somewhat more narrative in style and briefer than is typical for mathematics text books, even in the reform movement. Although it is not unique in focusing on social issues, it includes a number of examples and data sets that I have not seen elsewhere. Its intensive incorporation of data-driven group activities, following $U Q W$, is unusual for college algebra. Finally, the choice of content, while still fitting within the definition of college algebra, also admittedly challenges assumptions many would hold regarding what college algebra content should be. I think it is clear that discussions within the mathematical community and elsewhere on that topic are likely to be ongoing for some time to come. I hope others will find $A M W$ a useful contribution in this respect. 


\section{Acknowledgments}

I would like to acknowledge the National Science Foundation for supporting the development of $A M W$, and my colleagues at Dakota Wesleyan University, Michael Farney, Rocky VonEye, and Joan Lubben, the latter who has used $A M W$ in classes here at DWU. Rose Decker, a current DWU student, assisted in the tabulation and analysis of course enrollment and test data. In addition, I am grateful to Todd Swanson and Janet Andersen not only for their work in producing Understanding Our Quantitative World, but also for their comments and suggestions, inspiration, and other assistance, especially during the year I was at Hope College.

\section{References}

Andersen, Janet, and Todd Swanson. 2005. Understanding our quantitative World. Washington DC: Mathematical Association of America.

Barrett, Gloria; North Carolina School of Science and Mathematics. 2000. Contemporary precalculus through applications. Chicago: Everyday Learning Corp.

Baxter Hastings, Nancy. 2002. Workshop precalculus: Discovery with graphing calculators. Emeryville CA: Key Curriculum Press.

— Florence S. Gordon, Sheldon P. Gordon, and Jack Narayan. 2006. A fresh start for collegiate mathematics: Rethinking the courses below calculus. MAA Notes 69. Washington DC: Mathematical Association of America.

Catalano, Michael T., Tanya L. Leise, and Thomas J. Pfaff. 2009. Measuring resource inequality: The Gini coefficient. Numeracy, 2(2), Article 4. http://dx.doi.org/10.5038/1936-4660.2.2.4 (accessed Dec. 10, 2009).

CBMS (Conference Board of the Mathematical Sciences). 2001 The mathematical education of teachers. Issues in Mathematics Education, 11. Providence, RI: American Mathematical Society.

Crauder, Bruce, Benny Evans, and Alan Noell. 2003 Functions and change: A modeling approach to college algebra. Boston: Houghton Mifflin.

Deffeyes, Kenneth S. 2001. Hubbert's Peak: The impending world oil shortage. Princeton NJ: Princeton University Press.

Gordon, Sheldon P., Florence S. Gordon, Alan C. Tucker, and Martha M. Siegel. 2004. Functioning in the real world: A precalculus experience, $2^{\text {nd }}$ ed. Boston: Addison-Wesley.

Harsbarger, Ronald J., and Lisa S. Yocco. 2004. College algebra in context with applications for managerial, life, and social sciences. Boston: Pearson/ Addison-Wesley. 
Kenschaft, Patricia Clark. 2002. Mathematics for human survival. Island Park NY: Whittier Pub., Inc.

Kime, Linda Almgren, Judy Clark, Norma M. Agras et al. 2001. Explorations in college algebra, $2^{\text {nd }}$ ed. New York: John Wiley \& Sons.

Madison, Bernard L, and Lynn Arthur Steen. 2008. Evolution of numeracy and the National Numeracy Network. Numeracy, 1(1), Article 2. http://dx.doi.org/ 10.5038/1936-4660.1.1.2 (accessed Dec. 10, 2009).

Putnam, Robert. 2000. Bowling alone: The collapse and revival of American community. New York: Simon \& Schuster.

Schaufele, Christopher, and Nancy Zumoff. 1999. Earth algebra: College algebra with applications to environmental issues, $2^{\text {nd }}$ ed. Reading Ma: Addison-Wesley.

Small, Donald B. 2004 Contemporary college algebra: Data, functions, modeling. Boston: McGraw-Hill Custom Publishing, 2002.

- 2006. College algebra: A course in crisis. In A fresh start for collegiate mathematics: Rethinking the courses below calculus, ed. Nancy Baxter Hastings, Nancy, Florence S. Gordon, Sheldon P. Gordon, and Jack Narayan, 83-89. MAA Notes 69. Washington DC: Mathematical Association of America..

Thierer, Adam. 1998. 20 ${ }^{\text {th }}$ Anniversary of Airline Deregulation: Cause for Celebration, Not Re-regulation. The Heritage Foundation, Backgrounder \#1173, April 22. http://www.heritage.org/Research/Regulation/BG1173.cfm (accessed Dec. 10, 2009). 